\title{
Educação Permanente Promovida Pelo NASF Junto a ESF: uma Possibilidade de Ampliar a Reflexão a Cerca do Cuidado em Saúde
}

\author{
Frederico, Deison Fernando \\ Mestrado em Saúde Coletiva Universidade Federal Fluminense e SMS/RJ — deisonf@hotmail.com
}

O presente relato de experiência tem o objetivo de dizer de algumas parcerias no processo de trabalho das equipes de Estratégia de Saúde da Família - ESF com a implantação do Núcleo de Apoio à Saúde da Família - NASF. o NASF aqui referido, foi implantado em Novembro de 2011 e atualmente é composto por um psicólogo, uma psiquiatra, uma fisioterapeuta, uma nutricionista e dois educadores físicos. Este NASF presta apoio a 12 equipes de ESF, distribuída em 3 unidades, sendo duas delas do tipo $B$ (unidade mista com ESF e $A B$ ) e outra do tipo a (unidade de ESF), locadas na zona norte do município do Rio de Janeiro/RJ. o município do Rio de Janeiro no ano de 2009 contava com uma cobertura de ESF de aproximadamente $5 \%$ e termina no ano de 2012 com uma média de 40\% de cobertura. Obteve-se uma rápida expansão da ESF, porém pela cultura de saúde focada no modelo hospitalocêntrico, sendo a capital do país com maior número de hospitais, por consequência um número grande de profissionais não tem uma formação voltada a Atenção Básica e menos ainda para a lógica e a configuração da Estratégia de Saúde da Família. Inclusive a própria Secretaria Municipal de Saúde - SMS, financia em parceria com a Escola Nacional de Saúde Pública Sergio Arouca - ENSP da Fundação Oswaldo Cruz - FIOCRUZ, curso de especialização e mestrado voltado à ESF, para auxiliar na formação de recursos humanos qualificado para a rede do município. o NASF também ocupa um lugar relevante para a ampliação do escopo de ações da ESF, e para uma reflexão crítica do cuidado em saúde sob a lógica da ESF, englobando além da assistência e reabilitação em saúde, a prevenção e a promoção da saúde. Inicialmente da implantação da equipe NASF, mesmo com oficinas para a apresentação do que seria o núcleo de apoio e sua proposta de trabalho, com ênfase no matriciamento, os profissionais em sua maioria apresentaram resistência. Pois queriam que o fluxo entre ESF e NASF, se desse a partir de encaminhamento no papel, fugindo da proposta de discussão de caso, atendimento compartilhado, visitas domiciliares conjuntas e elaboração de Projeto Terapêutico Singular - PTS. Os profissionais da ESF tinham dificuldade de entender que o matriciamento busca compartilhar conhecimentos comuns e responsabilidade sobre a saúde dos usuários e do território, e que de fato alguns conhecimentos não são possíveis de serem compartilhados, por ser do especialista e quando isto ocorrer será discutido entre a equipe de referência que no caso é a ESF e o apoio matricial que é o NASF, e então acordado o atendimento individual pelo apoiador matricial ou ainda se necessário o encaminhamento/compartilhamento à outro serviço de maior complexidade. Foi e esta sendo necessário ter claro que somos profissionais especialistas trabalhando na desconstrução da lógica do especialismo. Entendendo está lógica como o simples encaminhamento a outro profissional especialista e desse modo fracionando o usuário, deixando de compreende-lo na sua integralidade, um sujeito com história, contexto e subjetividade. Além das discussões dos casos e seus PTS, os apoiadores matriciais tem a tarefa de discutir o processo de trabalho da equipe, desde a reunião de equipe que deve ultrapassar as discussões administrativas de agenda do médico e enfermeiro, contemplando a discussão de casos entre a própria equipe de referencia, a eleição de prioridades da equipe e dos usuários, o perfil epidemiológico do território, elencando estratégias de prevenção e promoção de saúde, a metodologia aplicada em grupos de educação em saúde, dentre outras atribuições da ESF. Outro aspecto importante que o NASF 
tem discutido com as equipes, são as articulações intersetoriais/ interinstitucional, como setores da educação, desenvolvimento social, secretaria da pessoa com deficiência, conselho tutelar, defensoria pública ... Assim em mais de dois anos de construção da relação entre NASF e ESF a qual imaginávamos que seria mais próxima/íntima desde o início, dado a proposta da Portaria 154 de 2008 do Ministério da Saúde a qual institui prerrogativas ao NASF , como por exemplo, estar a nível de atenção primária em saúde como a ESF, não ser porta de entrada, ênfase na ferramenta do matriciamento, e outros. Percebemos que este fazer educação permanente em ato, que se dá pela discussão de um caso, pelo atendimento compartilhado, pela visita domiciliar conjunta, a discussão do facilitar um grupo de educação em saúde, da reflexão do perfil epidemiológico e as estratégias de prevenção e promoção da saúde, da articulação da rede e das políticas públicas em prol do cuidado aos usuários nas suas demandas, necessidades e desejos. Fomentando uma reflexão crítica do fazer dos profissionais de saúde e a construção de uma clínica ampliada dialógica.

Frederico, Deison Fernando. Educação Permanente Promovida Pelo Nasf Junto a Esf: uma Possibilidade de Ampliar a Reflexão a Cerca do Cuidado em Saúde. In: Anais do Congresso Internacional de Humanidades \& Humanização em Saúde [= Blucher Medical Proceedings, num.2, vol.1]. São Paulo: Editora Blucher, 2014. ISSN 2357-7282

DOI 10.5151/medpro-cihhs-10453 